\title{
ANALYSIS OF CLEAR AIR TURBULENCE DATA FOR MARCH 1962
}

\author{
DEVER COLSON \\ U.S. Weather Bureau, Washington, D.C. \\ [Manuscript received October 24, 1962; revised December 10, 1962]
}

\begin{abstract}
A special intensive collection of complete flight data for flights above 18,000 ft. MSL furnished detailed data on areas of non-occurrence as well as areas of occurrence of high level turbulence during a selected 5-day period in March 1962. The data were tabulated by $2.5^{\circ}$ latitude-longitude "squares." Frequency distributions and probabilities of turbulence occurrence were computed over individual squares, area configurations, flight elevations, time of day, and for varying values of such meteorological parameters as vertical and horizontal wind shear, location and intensity of jet stream, wind speed, temperature and height of tropopause, Richardson number, flight direction, changes in air temperature, and high elouds.

The probability of turbulence occurrence increases fairly uniformly with changes in the value of the vertical wind shear, wind speed, and the Richardson number. The probability of turbulence occurrence responds more erratically with the ehanges in the values of other parameters, particularly horizontal wind shear. There.appears to be no significant relation between the probability of turbulence occurrence and time of day, flight direction, and height and temperature of the tropopause. Presence of high clouds appears to increase the probability-of turbulence occurrence.
\end{abstract}

\section{INTRODUCTION}

In many clear air turbulence $\left(\mathrm{CA}^{\prime} \mathrm{T}\right)$ studies, only the areas of turbulence are known. It is not known whether there was no-turbulence in the other areas or simply that there were no flights over other areas at that time. During a selected 5-day period in March 1962, the commercial airlines: were asked to fill out complete flight data cards (fig. 1) for all flights at 18,000 ft. MSL or higher across continental United States. The pilots were asked to submit the data cards whether turbulence was encountered or not. Thus, the areas of non-occurrence as well as the areas of occurrence of turbulence could be determined and analyzed. It was also possible to compute the probability of the occurrence of turbulence under different meteorological conditions.

The original date of the test was from 0000 GMT March 12 through 0000 GMT March 17, 1962. In addition to commercial flight data, reports from military flight operations were obtained from the National Weather Records Center at Asheville and the Air Weather Service CAT Forecast Office at Kansas City. However, one of the major airlines was unable to participate during the above period but did submit data from 0000 GMT March 19 through 0000 GMT March 24, 1962. These reports were sufficient in number that when combined with the additional military data for that period a second 5-day test period was available. I wish to thank the commercial airlines, the Air Transport Association of America, and Air Weather Service for their excellent cooperation in obtaining the data for this study.

\section{METHOD OF ANALYSIS}

The continental United States was divided into $2.5^{\circ}$ latitude and longitude "squares." The data cards were examined for the intensity of turbulence occurrences at four flight altitudes over each square: (1) 32,000 and higher, (2) 29,000 to 31,999 , (3) 26,000 to 28,999 , and (4) below $26,000 \mathrm{ft}$. The intensity classes were: none, light, moderate, and severe. Tabulations were made for 6-hr. intervals centered on the standard synoptic times: 0300 to 0859,0900 to 1459,1500 to 2059 , and 2100 to 0259 GMT. The tabulations included the total number of flights, the number of occurrences of the different classes of turbulence for each flight layer and time interval over each square. Computations were made of the probabilities of the different turbulence intensities by time intervals, flight layers, over individual squares, or other area configurations. Since the study was concerned with non-convective type turbulence, occurrences were not used if the data card reported the turbulence in the vicinity of towering cumuli or thunderstorms and also in squares where the surface map indicated well developed thunderstorm areas.

During the two 5-day test periods, some-12,389 flight

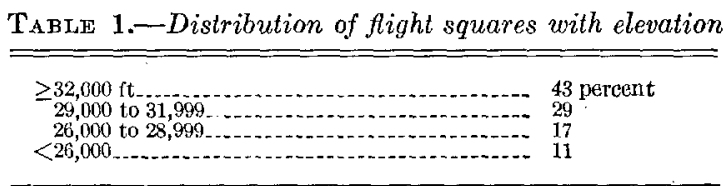




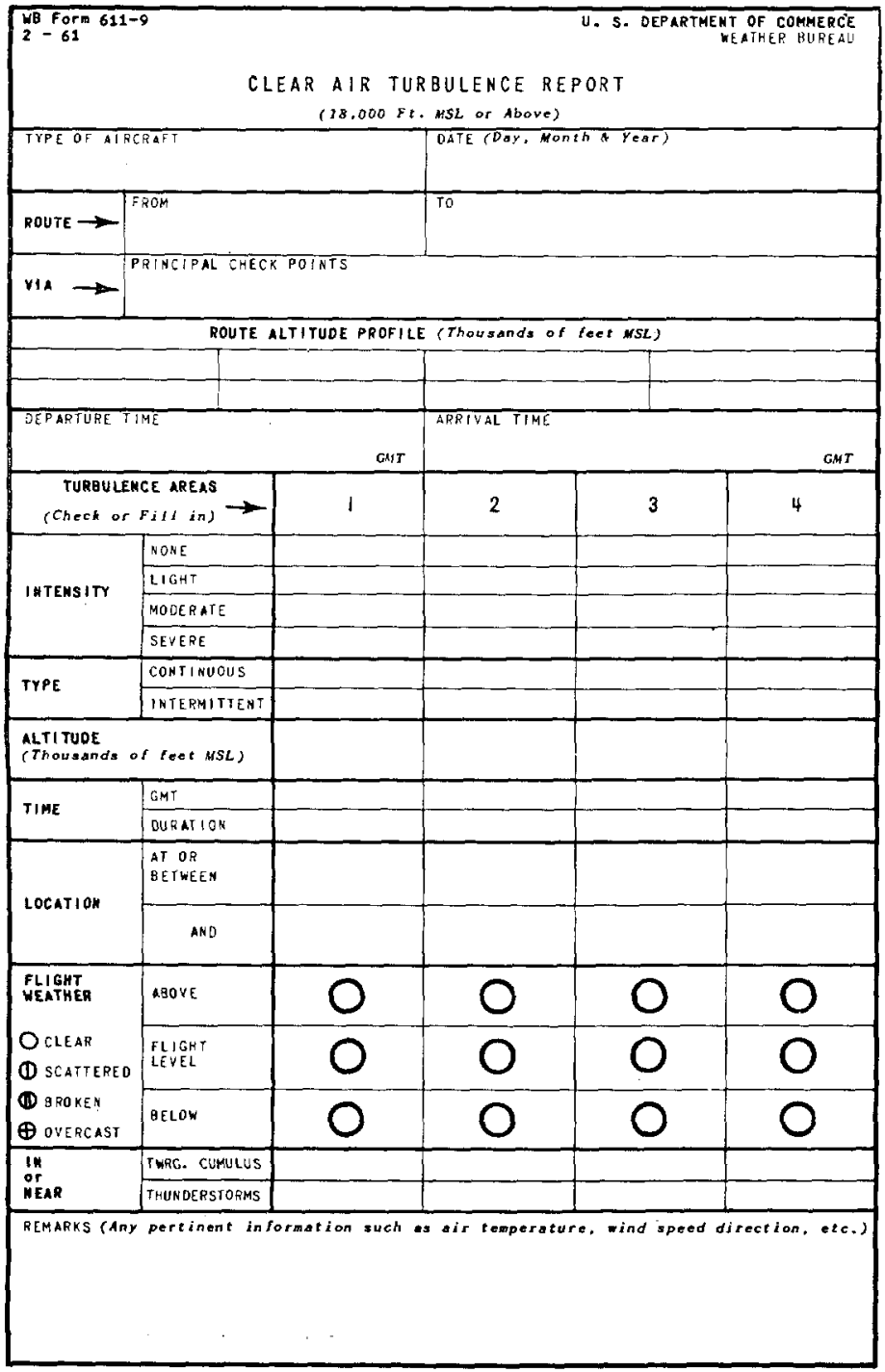

Figure 1.-Turbulence reporting card.

squares were involved. The number of flights varied considerably in locations, elevation, and time of day. Table 1 shows the distribution of flight squares by altitude intervals.

The aerial distribution of the flight squares is shown in figure 2. The larger numbers are along the major air routes and near the major air terminals across the country.

\section{RESULTS \\ GENERAL}

The actual distribution of the turbulence occurrences during the two 5-day periods is shown in table 2 . With one exception, there were some moderate or severe turbulence occurrences in each 6-hr. period. However, there were definite peaks from 1500 March 14 to 0900 March 15, from 0.900 March 20 to 1500 March 21, and from 1500 March 22 to 0900 March 23. Outside of these peak periods, both the percent of squares with no tur-

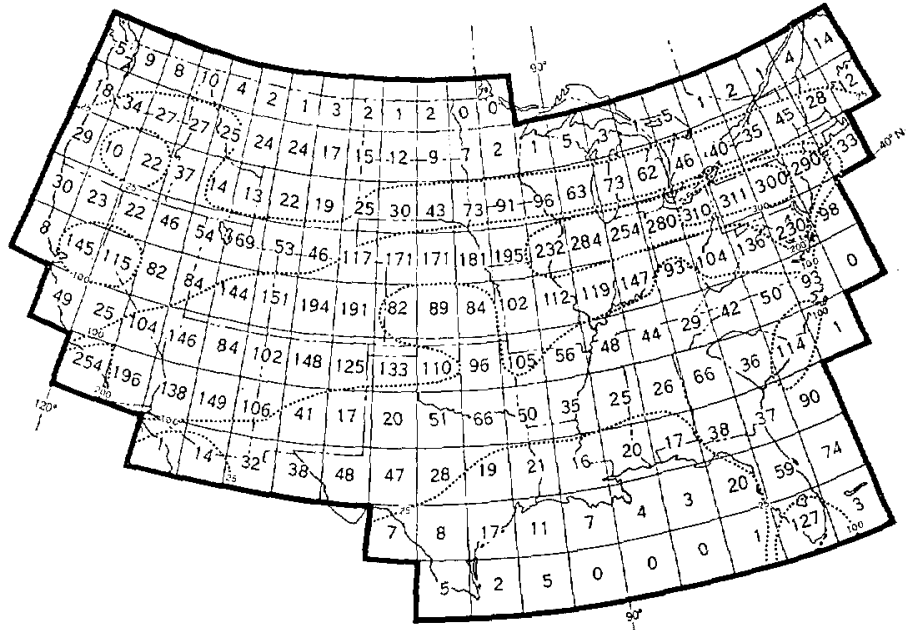

Figure 2.--Flight distribution over the 5-day period March 12 through 16, 1962.

bulence and of those with some intensity of turbulence was fairly consistent. The overall distribution of occurrences by different intensity classifications is shown in the sub-totals for each 5-day period and the grand total at the bottom. The distributions for the two 5-day periods

TABLE 2,-Calendar of turbulence occurrences

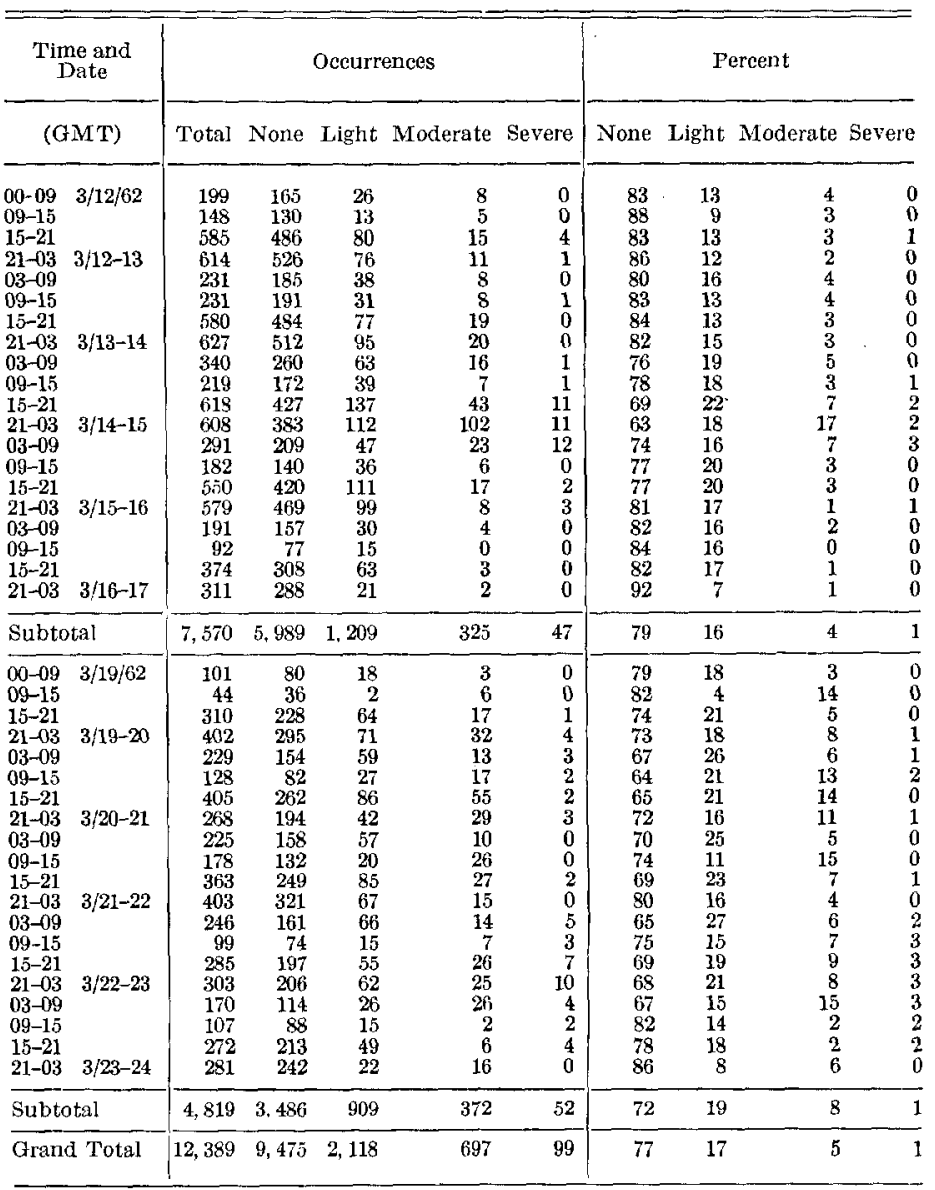




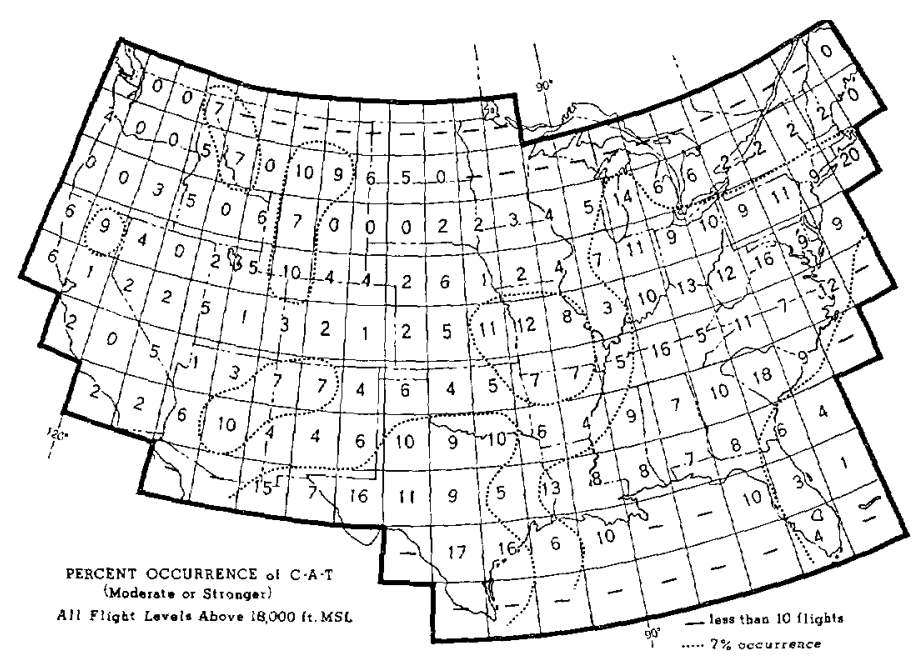

Figure 3.--Geographical distribution of the percent occurrence of moderate or severe turbulence, for flights at all levels combined.

were quite similar. The combined totals show:

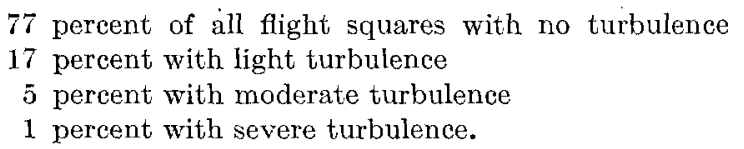

It can be seen that there was a 23 percent chance of some degree of turbulence and a 6 percent chance of moderate or severe turbulence over any particular square.

The distribution of the probability of moderate or severe turbulence by squares for the two 5-day periods is shown in figure 3. The dotted line is the dividing line between above and below average chance of turbulence.

The distribution of the probability of moderate or severe turbulence by squares for flights below 29,000 ft. is shown in figure 4 . The similar distribution for flights at $29,000 \mathrm{ft}$. and above is shown in figure 5 . The average probability of moderate or severe turbulence is 9 percent for flights below $29,000 \mathrm{ft}$. and 5 percent for flights at $29,000 \mathrm{ft}$. or above. The dotted lines on the charts are the dividing lines between above and below average chance of turbulence on each chart. The areas of above average probability are in fairly good agreement for the two layers except for an additional area for the higher-leve] flights over the Rockies, which is probably associated with mountain-wave type turbulence occurrences.

The difference in the probability of turbulence at different flight levels is shown more effectively in figure 6 . The distribution of the number of squares with no turbulence and light turbulence follows the pattern for the total number of flights. The distribution for moderate turbulence is a bit more weighted for the lower layers and there is a decided increase in the importance of the lower layers for the severe occurrences. It is difficult to determine whether this is real or simply due to the fact that more of these occurrences may have been during landing or take-off flight patterns.

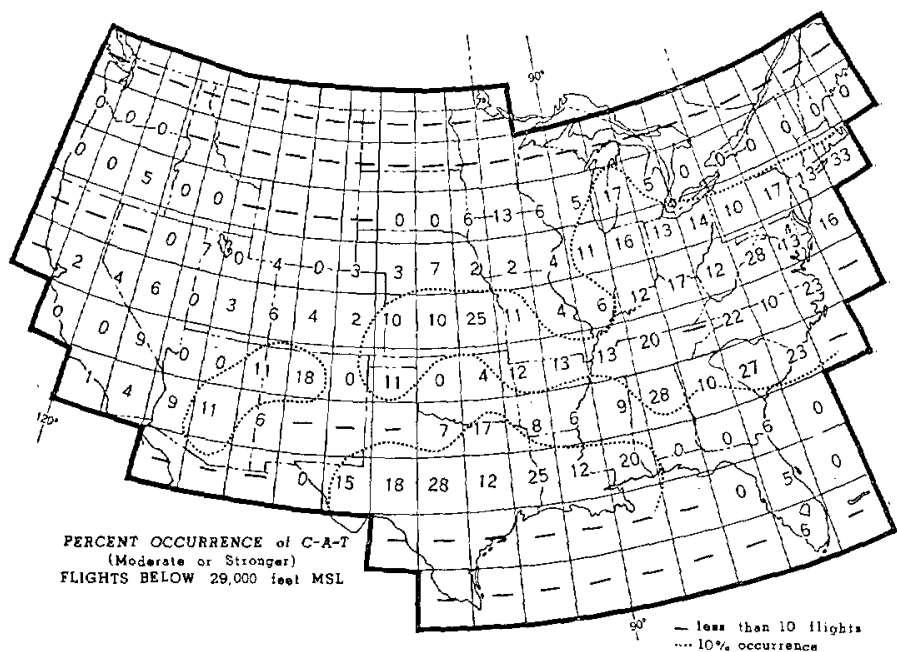

Frgcre 4.-Geographical distribution of the percent occurrence of moderate or severe turbulence for flights below $29,000 \mathrm{f} t$.

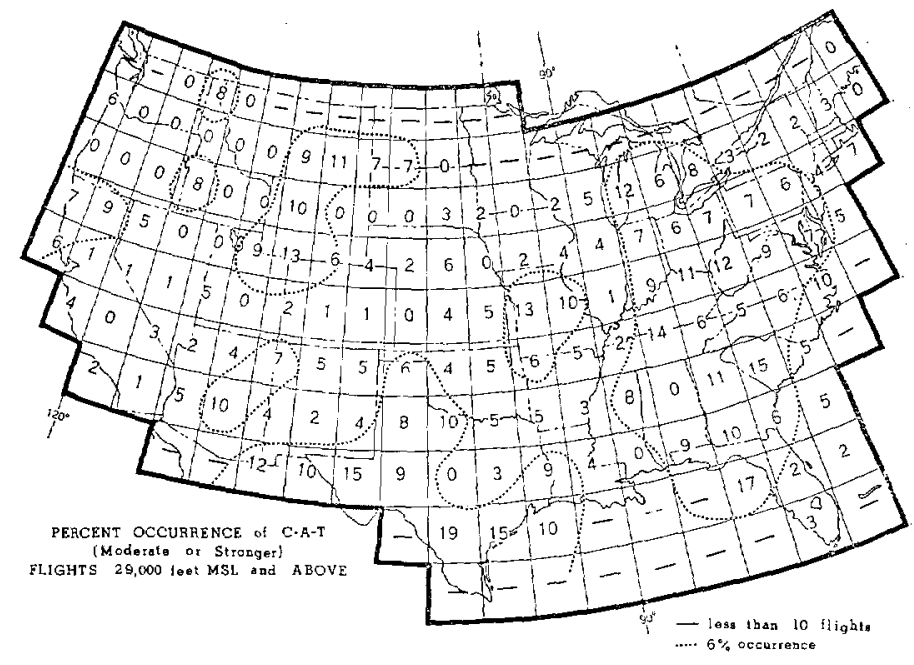

Figure 5.-Geographical distribution of the percent oceurrence of moderate or severe turbulence for fights at $29,000 \mathrm{ft}$. and above.

While there was considerable difference in the number of fights during the different 6 -hr. periods, the percent occurrence of turbulence, as given in table 3 shows no significant variation with the time of day.

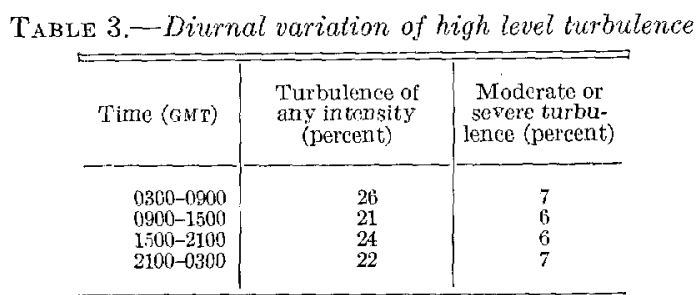




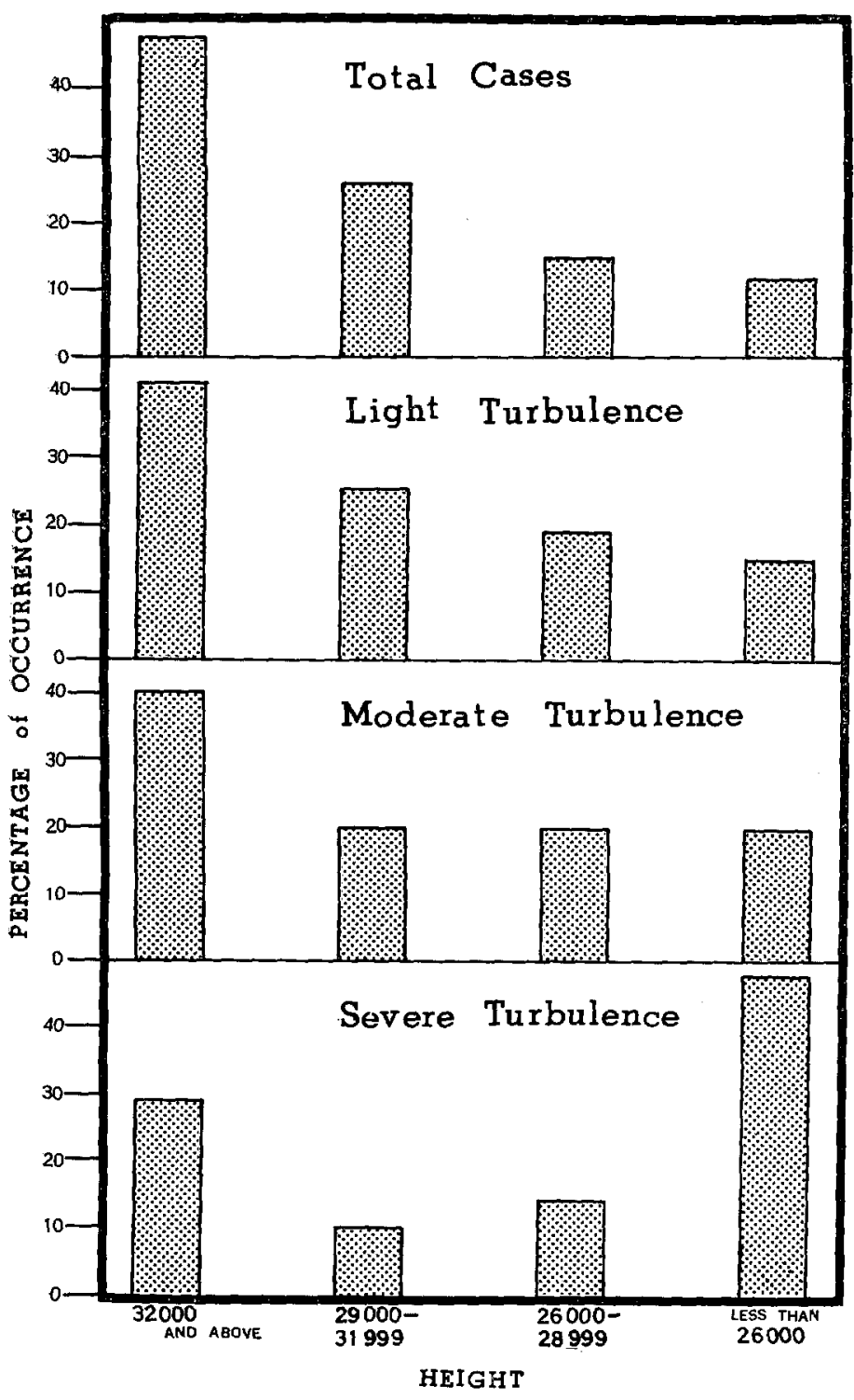

FIGURE 6.--Distribution of percent occurrence of turbulence with height.

One of the most intense periods of turbulence was during the 6 -hr. period from 2100 GMT March 14 through 0300 GMT March 15. In figure 7 , the numbers in each square indicate the total number of flights and the combined number of moderate or severe turbulence occurrences. Typical squares in the more intense turbulence region are 14 occurrences out of 27 flights, 12 out of 30,15 out of 31 , 19 out of 33 , and 16 out of 30 flights. It is interesting to note that with any reasonable number of flights, the largest chance of moderate or severe turbulence is not much more than 50 percent.

The above data indicate the importance of the use of probability in analysis and forecasting of CAT. It is unlikely that there will be areas where more than $\mathbf{5 0}$ percent of the flights will meet moderate or severe CAT. On the other hand, there will be many scattered areas with very few occurrences.

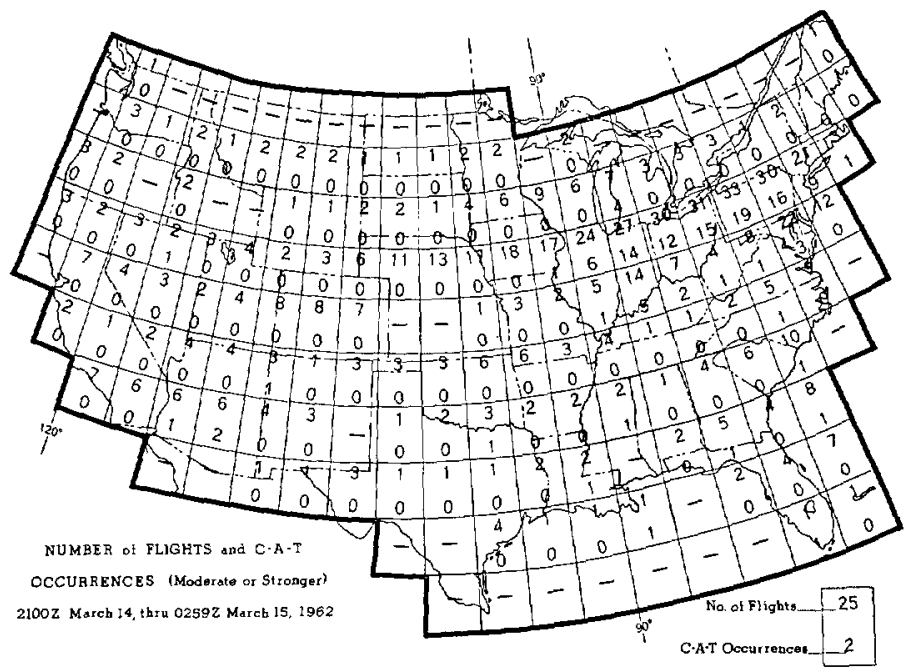

FIGURE 7.-Number of flights and number of moderate or severe turbulence oceurrences by latitude-longitude squares for the period 2100 GMT March 14 through 0259 GMT March 15, 1962.

In forecasting high level turbulence, it may be necessary to limit the forecasting to the more likely areas of turbulence. This will not mean that all planes flying across these areas and at these elevations will experience turbulence or that there will be no chance of turbulence in the other areas.

An examination of the peak periods of moderate or severe turbulence, mentioned earlier in the paper, shows some interesting meteorological patterns and developments. The $300-\mathrm{mb}$. charts for the period 1200 GMT March 14 to 1200 GMT March 15 are shown in figure 8 . During this period the polar jet was displaced to the north with an intensification of the wind field to the north of the jet axis. There was an unusually large number of moderate or severe occurrences in the vicinity of and to the north of the jet axis through Indiana, Ohio, and Pennsylvania. This was evident in figure 7 . Both the horizontal and vertical wind shears became large in this area. The National Meteorological Center's (NMC) Maximum Wind Analysis Chart for this period revealed smoothed vertical wind shears of $8 \mathrm{kt}$. per $1000 \mathrm{ft}$. or greater.

The sequence of Maximum Wind Analysis charts for the period $0000 \mathrm{GMT}$ March 22 to 0000 GMT March 23 is shown in figure 9 , along with the location of the moderate or severe turbulence occurrences. The trough in the west at 0000 GMr March 22 moved rapidly eastward. The high wind speeds ahead of the trough along with the turbulence occurrences moved eastward ahead of the trough. A majority of the occurrences were on the left or cold side of the jet but there were numerous occurrences on the right and at 0000 GMr March 23 between the two jet axes.

\section{SPECIFIC METEOROLOGICAL PARAMETERS}

The following section is devoted to the influence of such meteorological parameters as vertical wind shear, hori- 

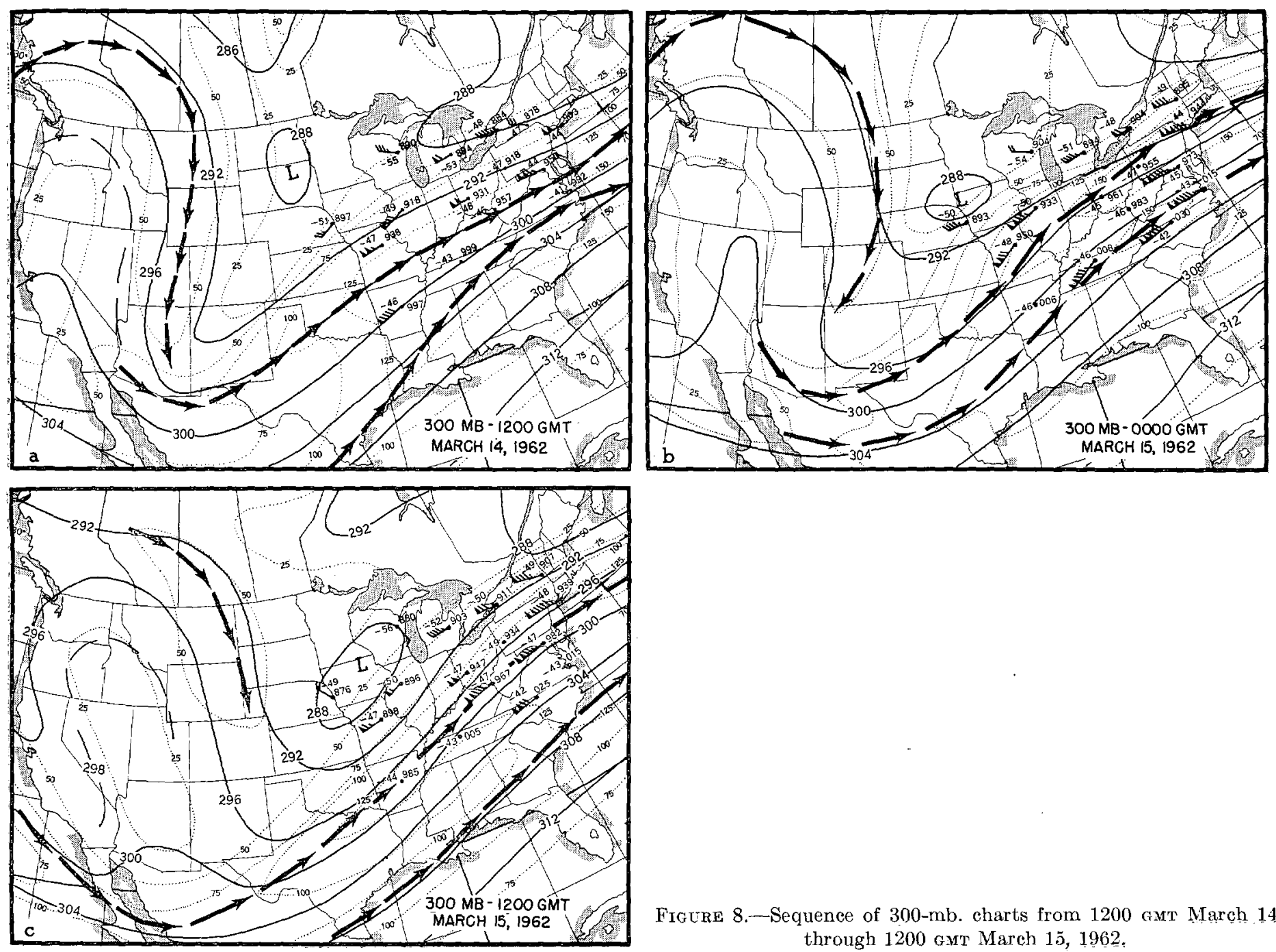

Figure 8.-Sequence of 300-mb. charts from 1200 GMT March 14 through $1200 \mathrm{GMT}$ March 15, 1962.

zontal wind shear, jet stream, wind speed, tropopause height and temperature, and the Richardson number (which combines vertical wind shear and temperature lapse rate or stability). The results will be expressed in the probability of moderate or severe turbulence with varying values of these variables.

Vertical Wind Shear.-Vertical wind shear has been regarded as one of the most important variables by many research workers including Clem [1], Colson [2], and George [3] but has been minimized by Harrison [4]. The data were divided into two layers, (1) flight squares above $29,000 \mathrm{ft}$. and (2) flight squares below $29,000 \mathrm{ft}$. Vertical wind shears were read and tabulated for each square from the NMC vertical wind shear analysis charts. This is a smoothed evaluation of the vertical wind shear over a deep layer covering $10,000 \mathrm{ft}$. above and below maximum wind level. However, this parameter is easily available for both analysis and forecast operations.

The squares were classified into those with vertical wind shears of less than $4 \mathrm{kt}$. and those with vertical shear equal to or greater than $4 \mathrm{kt}$. per $1000 \mathrm{ft}$. Additional classifications were made for squares with vertical wind shears equal to or greater than 6 and $8 \mathrm{kt}$./1000 ft., respectively. The chance of moderate or severe turbulence was computed in each of these classifications.

The results, as shown in figure 10, indicate an 11 percent chance of moderate or severe turbulence with vertical wind shears equal to or greater than $4 \mathrm{kt} . / 1000 \mathrm{ft}$. as compared to only 3 percent chance with vertical wind shears of less than $4 \mathrm{kt} . / 1000 \mathrm{ft}$. The chance of moderate or severe turbulence increased to 19 and 34 percent respectively with vertical wind shears of 6 or $8 \mathrm{kt} / 1000 \mathrm{ft}$. or more.

This steady increase in the probability of moderate or severe turbulence was also present in the flight squares both above and below 29,000 ft. The largest probability was 46 percent for flight squares below $29,000 \mathrm{ft}$. with vertical wind shear of $8 \mathrm{kt} . / 1000 \mathrm{ft}$. or more. This steady increase in the probability of moderate or severe turbulence 

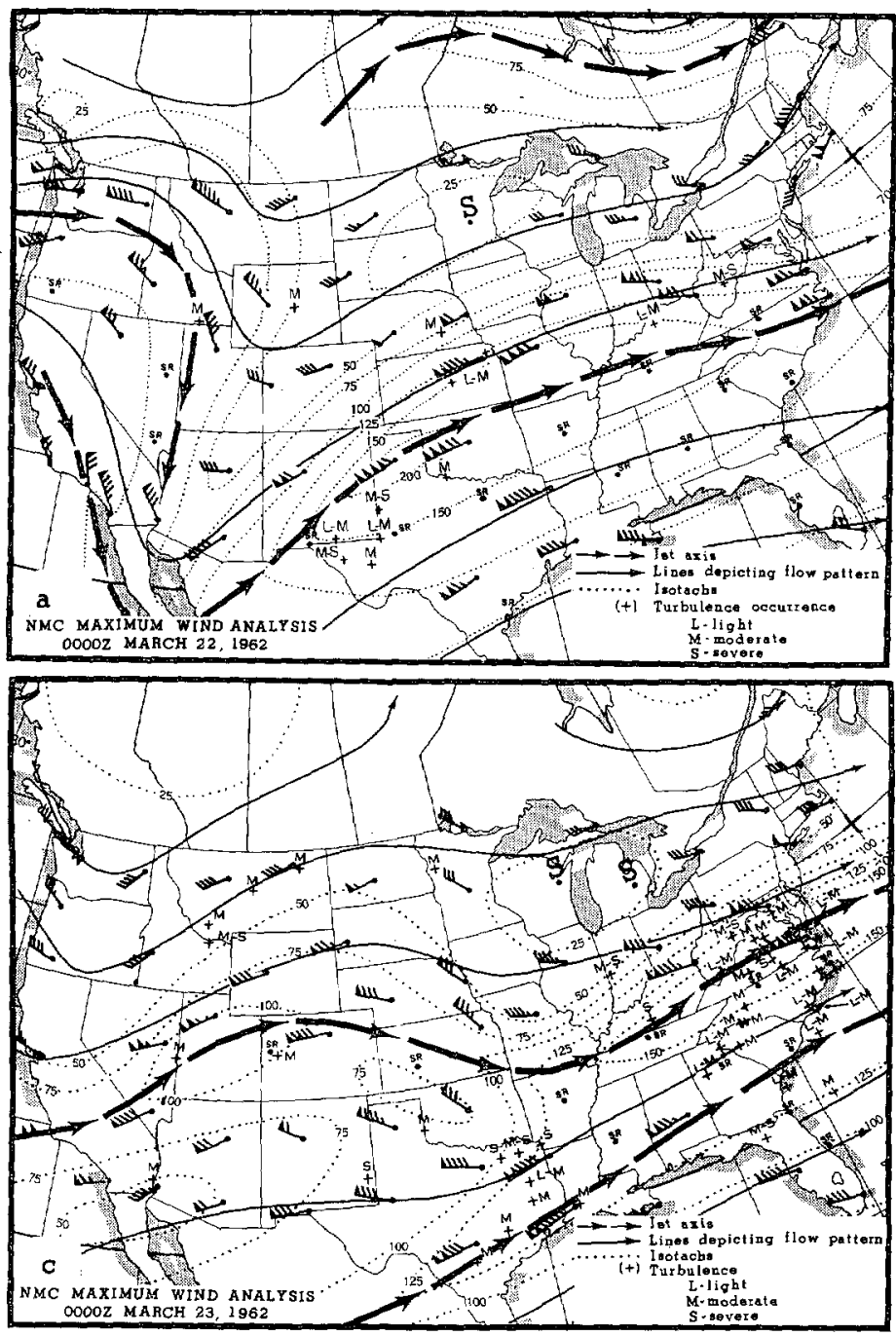

with increasing vertical wind shear indicates that vertical wind shear should be a very useful forecasting tool.

Since many workers (e.g., George [3]) have been using the more detailed vertical wind shears from the original teletypewriter data, it is useful to examine the question of vertical wind shear in more detail. The data in table 4 summarize the relation between the smoothed vertical wind shears and the more detailed vertical wind shears. The numbers give the percent of the detailed vertical wind shears equal to or greater than 10 and $15 \mathrm{kt} . / 1000$

TABLE 4.--Comparison of detailed verlical wind shears with NMC smoothed vertical wind shears

\begin{tabular}{|c|c|c|c|}
\hline & \multicolumn{3}{|c|}{ With NMC smoothed vertical shears of } \\
\hline & $\geq 1$ & $\geq 6$ & $\geq 8 \mathrm{kt} . / 1000 \mathrm{ft}$. \\
\hline $\begin{aligned} \text { Chance of detailed vertical shears of: } & \text { - } \\
& \geq 10 \mathrm{kt} .1000 \mathrm{ft} \text {. }\end{aligned}$ & $\begin{array}{c}\text { (percent) } \\
44 \\
13\end{array}$ & $\begin{array}{c}\text { (percent) } \\
58 \\
20\end{array}$ & $\begin{array}{c}\text { (percent) } \\
61 \\
24\end{array}$ \\
\hline
\end{tabular}

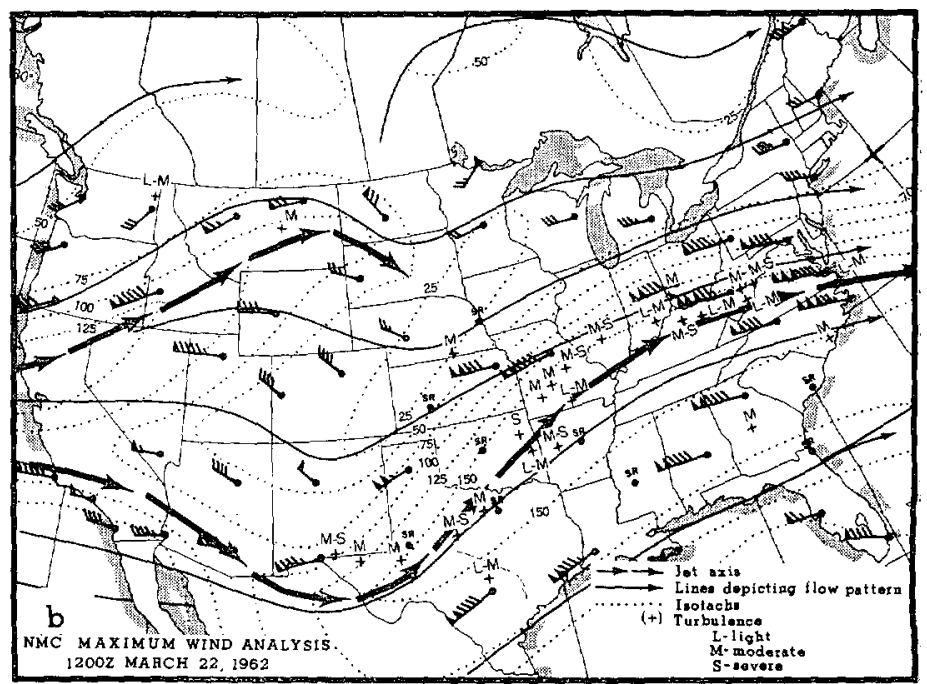

Figure 9.-Sequence of NMC Maximum Wind Analysis charts from 0000 GMT March 22 to 0000 GMT March 23, 1962. Also shown are oceurrences of moderate or severe turbulence. ft. when the smoothed shears are 4,6 , and $8 \mathrm{kt} . / 1000 \mathrm{ft}$. or more respectively. These results indicate that larger vertical wind shears are increasingly likely as the NMC smoothed vertical wind shears increase from 4 to 6 and 8 $\mathrm{kt} . / 1000 \mathrm{ft}$. or more.

Figure 1.1 shows the distribution of the mean vertical wind shears taken from the original teletypewriter data at the individual rawinsonde stations during the two test periods. The numbers indicate the percent of time that the detailed vertical wind shears were $6-9,10-14$, and 15 $\mathrm{kt} . / 1000 \mathrm{ft}$. or more at each station. The superimposed line shows the separation between above and below average probability of moderate or severe turbulence occurrences. The areas of above average chance of moderate or severe turbulence occurrences agree well with the areas of greater percent of the larger vertical wind shears except possibly for an area over the Rocky Mountains. This would be expected since extremely large vertical wind shears are not so essential in the mountain wave mechanism (Colson [5]).

Horizontal Wind Shear.-The horizontal wind shear 

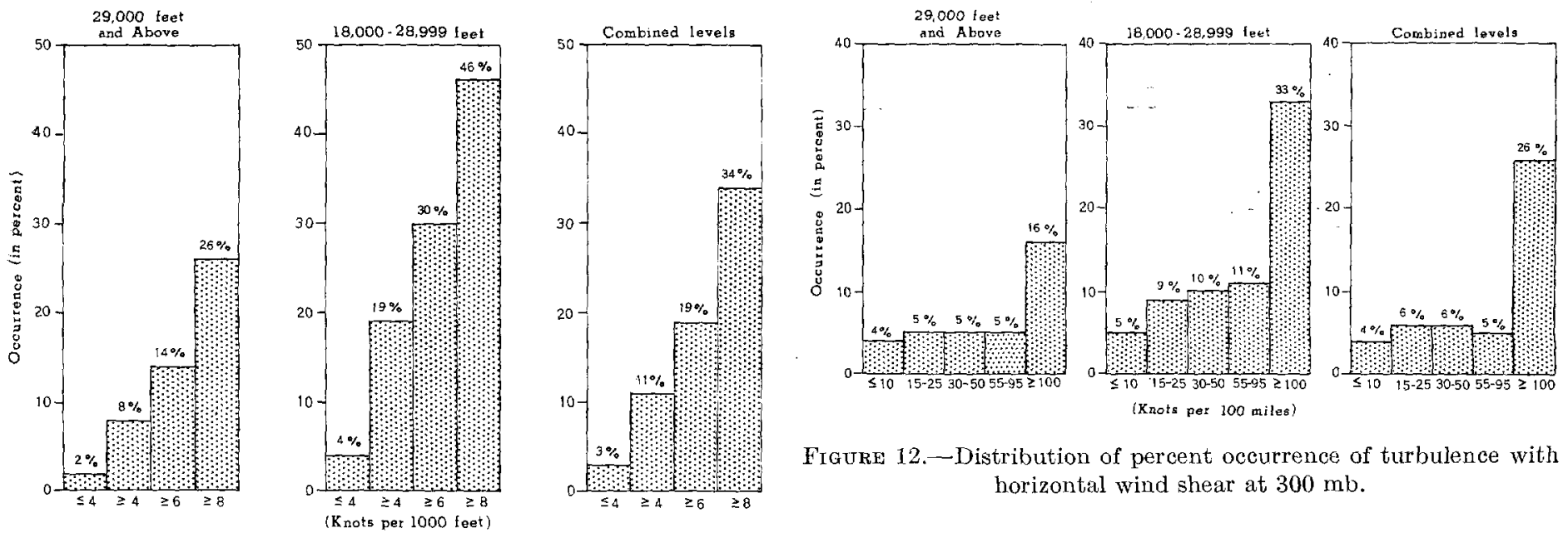

Figure 12.-Distribution of percent occurrence of turbulence with horizontal wind shear at $300 \mathrm{mb}$.

FiguRe 10.-Distribution of percent occurrence of turbulence with vertical wind shear (from NMC smoothed charts).

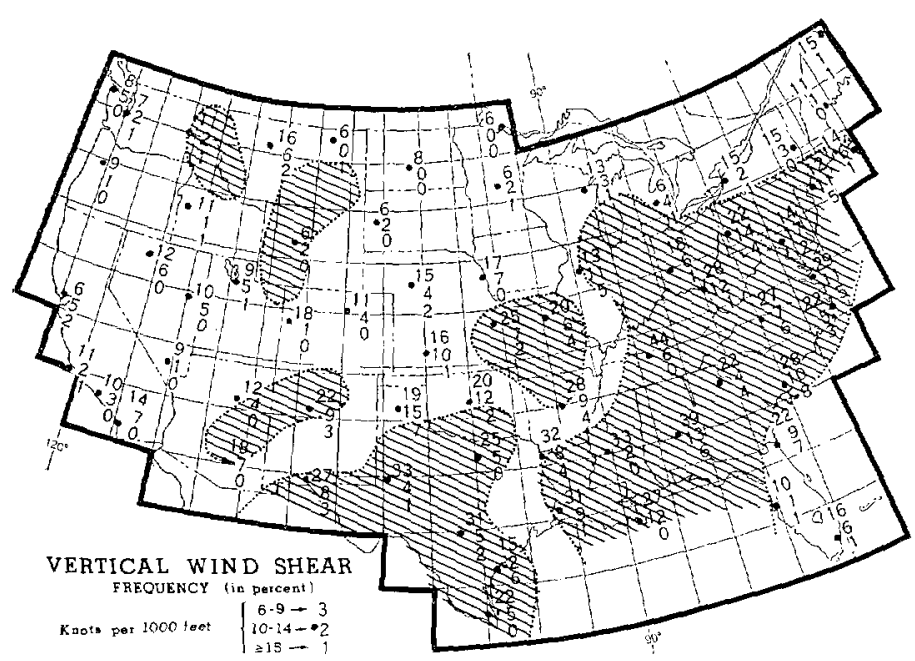

FIGURE 11.-Distribution of detailed vertical wind shear. Shading shows areas of above average probability of occurrence of moderate or severe turbulence.

data for each square were obtained from the spacing of the isotachs on the analyzed NMC $300-\mathrm{mb}$. charts. The probability of moderate or severe turbulence was computed for horizontal shear classes (in kt./100 mi.) of (1) less than 10, (2) 15 to 25, (3) 30 to 50, (4) 55 to 95 , and (5) 100 or more. The results, as shown in figure 12, indicate that the chance of moderate or severe turbulence does not show any uniform or significant increase with increasing horizontal wind shear until shears of $100 \mathrm{kt} / 100 \mathrm{mi}$. are equalled.

Jet Stream.-The flight squares were checked for the presence or absence of a jet stream as indicated on the NMC analyzed $300-\mathrm{mb}$. charts. The probability of -occurrences of moderate or severe turbulence was determined for squares with and without a jet axis over the square. The results for flights above and below 29,000

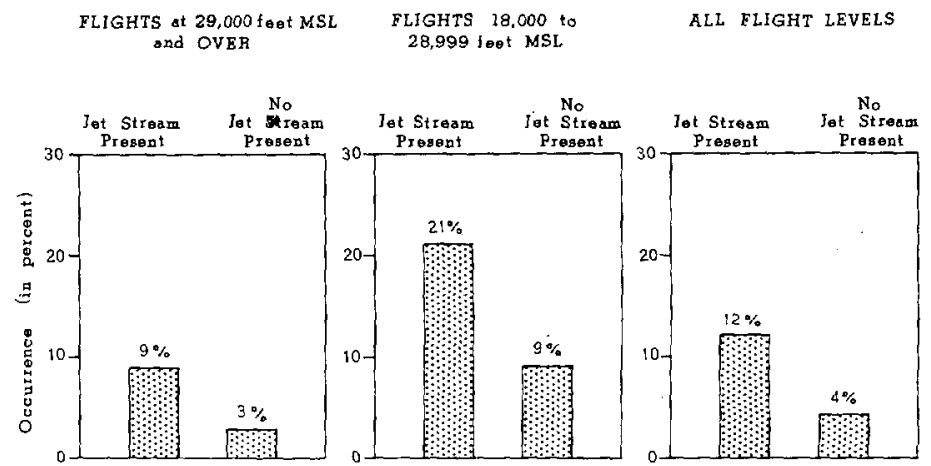

Frgure 13.-Association of the percent occurrence of turbulence with presence of jet stream at $300 \mathrm{mb}$.

ft. and for all levels are summarized in figure 13. The presence of the jet stream does increase the chance of moderate or severe turbulence but the probability does not appear as high as might be expected in light of the great emphasis which has been placed on this parameter. From an inspection of the individual $300-\mathrm{mb}$. charts it appears that there are many segments of the jet axis without any turbulence occurrences. Even though the level of the jet axis was fairly high during the test periods, the presence of the jet stream seems to be more effective for turbulence in the lower layers.

When the occurrence data were restricted to the squares within the 150-kt. isotach along the jet stream on the $300-\mathrm{mb}$. chart, the probability of moderate or severe turbulence increased to 16 percent for the upper layer, 26 percent for the lower layer, and 20 percent for flights at all levels.

Wind Speed.-The wind speed was determined for each flight square from the NMC analyzed $300-\mathrm{mb}$. charts. The results, given in table 5 , indicate an increase in the probability of moderate or severe turbulence with increasing wind speeds, at least above $50 \mathrm{kt}$. However, the percent of occurrences is not as high and as conclusive ās might have been expected. 
TABLE 5.- Effect of wind speed

\begin{tabular}{|c|c|c|c|}
\hline Wind speed (kt.) & $\begin{array}{l}\text { Flight squares } \\
\text { above } 29,000 \text { it. }\end{array}$ & $\begin{array}{l}\text { Flight squares } \\
\text { below } 29,000 \mathrm{ft} \text {. }\end{array}$ & $\begin{array}{c}\text { Flight squares } \\
\text { at all levels }\end{array}$ \\
\hline $\begin{array}{l}<25 \\
250-50 \\
50-100 \\
100-150\end{array}>150 \ldots$ & $\begin{array}{c}\text { (percent) } \\
2 \\
2 \\
4 \\
5 \\
16\end{array}$ & $\begin{array}{c}\text { (percent) } \\
\mathbf{3} \\
\mathbf{3} \\
\mathbf{8} \\
15 \\
26\end{array}$ & $\begin{array}{c}\text { (percent) } \\
2 \\
2 \\
5 \\
8 \\
20\end{array}$ \\
\hline
\end{tabular}

Tropopause.-The data for the height and temperature of the tropopause were taken from the teletypewriter reports from each rawinsonde station and interpolated for the other flight squares. The turbulence occurrences were for the $6-\mathrm{hr}$. periods centered on the synoptic times, 0900 to 1500 and 2100 to 0300 GMT and the changes in the tropopause height and temperature were for the 12 hours up to these particular synoptic times, 1200 and 0000 GMT. The results, shown in table 6 , are not conclusive. There appears to be a slightly greater chance of moderate or severe turbulence when the tropopause is rising and becoming colder but this difference does not appear to be significant.

The heights of the tropopause were read and tabulated for each square. These heights were divided into 5 classes: (1) below 25,000 , (2) 25,000 to 30,000, (3) 30,000 to 35,000 , (4) 35,000 to 40,000 , and (5) above $40,000 \mathrm{ft}$. The turbulence occurrences were limited to those in the 6-hr. period centered about the synoptic times: 0900 to 1500 and 2100 to $0300 \mathrm{GMT}$. The results, shown in table 7 , again are not conclusive except that there is a slight but irregular trend for greater probability of moderate or severe turbulence with increasing height of the tropopause. This does not appear to be a useful parameter in forecasting turbulence.

Richardson Number.- The Richardson number has been one of the more controversial parameters in the study of high-level turbulence. This number combines vertical wind shear and the temperature lapse rate or stability. Some workers, including Brundige [6], Mook [7], Lake [8], and Reiter [9] have found a poor correlation but others, including Anderson [10], Pinus [11], and Kroll and Rustenbeck [12], have found some correlation. One basic difficulty is the determination of the exact value of the Richardson number at the location, level, and time of the reported turbulence with the present upper-air network of stations $100-200 \mathrm{mi}$. apart with observations every 6 or $12 \mathrm{hr}$.

The Richardson numbers were computed for the layers:

TABLA 6.-12-hr. changes in height and tempercture of tropopause $=$ Higher and colder...................... (percent $)$ (percent $)$

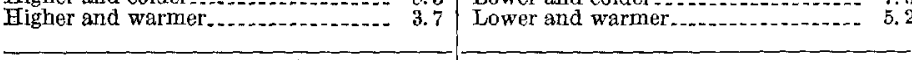

Colder.

Warmer-

Higher.

7.5
TABLE 7.-Effect of height of tropopause

\begin{tabular}{ll|r|r|r|r|r}
\hline & \multicolumn{3}{|c|}{ Tropopause beight (ft.) } \\
\hline & Below & 25,000 & $30,000-$ & $35,000-$ & Above \\
& 25,000 & 30,000 & 35,000 & 40,000 & 40,000 \\
\hline & & & & & & \\
\hline
\end{tabular}

$500-400,400-300,300-250,250-200 \mathrm{mb}$. The maximum vertical wind shear was determined from the teletypewriter data for each layer along with the temperature lapse rate at each rawinsonde station. The two Richardson numbers in each of the two larger layers, 500-400-300 and 300-250-200 mb. were classified as follows: (1) both values below $1,(2)$ one value below $1,(3)$ both values between 1 and 4, (4) one value between 1 and 4 , and (5) both values above 4 . These class values were plotted on a map at the proper locations. The values of the Richardson number class interval for the intermediate squares were interpolated. The turbulence occurrences were limited to the 6-hr. periods centered on the synoptic times: 0900 to 1500 and 2100 to $0300 \mathrm{GMT}$.

The results (fig. 14) indicate the best correlation for flight squares below $29,000 \mathrm{ft}$. and the Richardson number classification in the 500-400-300-mb. layer. The probability of moderate or severe turbulence decreases with an increase in the Richardson number classification. The probability of moderate or severe turbulence is about 5 times greater for squares with at least one Richardson number $(500-400-300 \mathrm{mb}$.) less than 1 than for squares with both Richardson numbers over 4 .

There appears to be some relation between the turbulence occurrences for flight data below $29,000 \mathrm{ft}$. and the Richardson number classification in the upper layer (300-250-200 mb.) but this relationship is not as consistent as that shown in the previous paragraph. The turbulence occurrences for flight data above $29,000 \mathrm{ft}$. do not fit with any regular progression of the Richardson number classification in either layer. However, there is a greater chance of moderate or severe turbulence with one Richardson number less than 1 than for both numbers over 4.

Flight Direction.--There have been many suggestions about the possible effect of flight direction on the occurrence of turbulence. The original flight cards furnished an excellent source of data. The reports of the different intensities of turbulence occurrences were tabulated for each predominant flight direction: north, south, east, or west (table 8).

During this test period, the general flow and the orientation of the jet streams were predominantly west to east. While the combined north and south bound flights indicated a slightly lower chance of turbulence than the combined east and west bound flights, the differences certainly do not appear to be significant. 


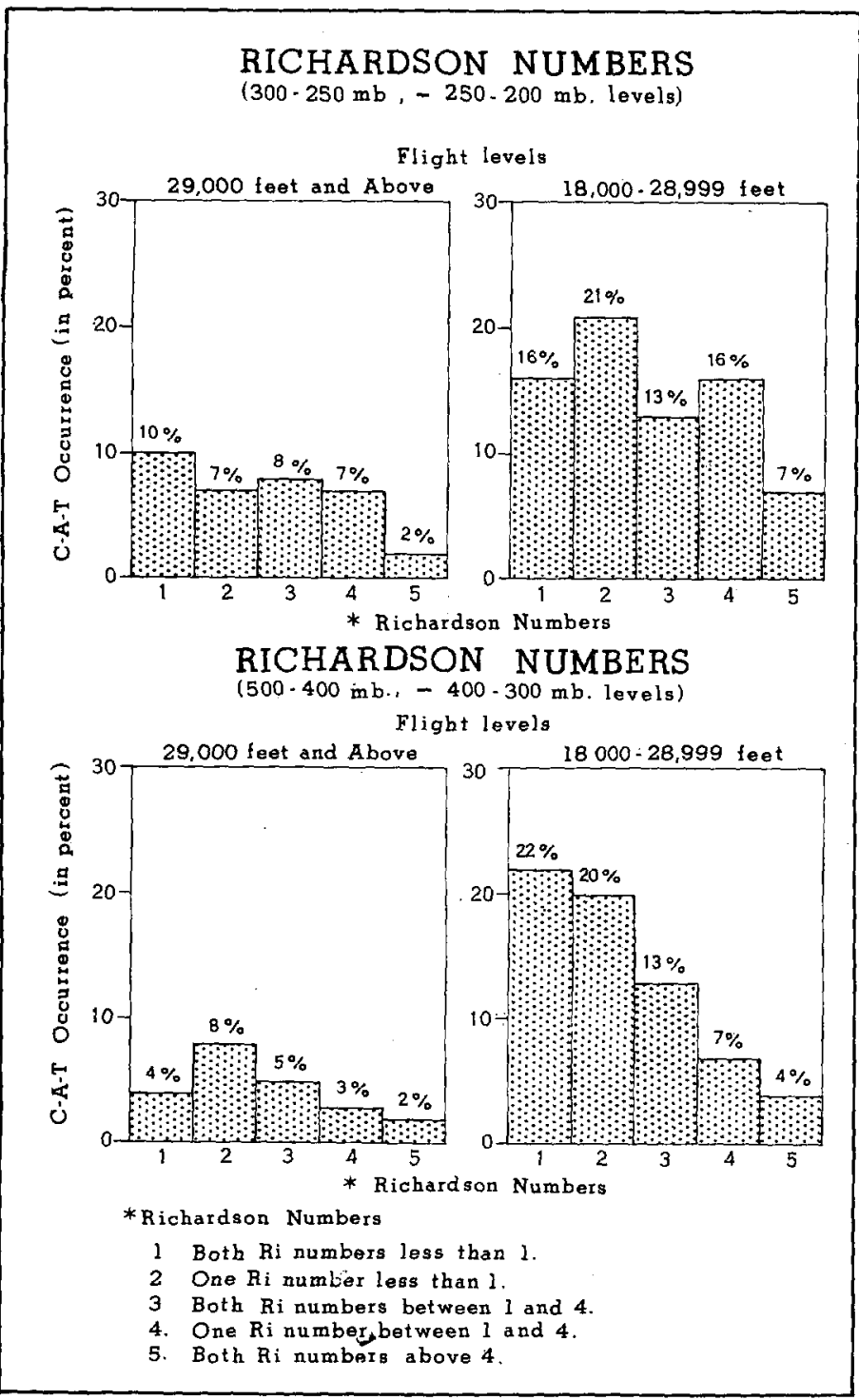

FiguRE 14.-Distribution of the percent occurrence of turbulence with Richardson numbers.

Temperature and clouds.-An examination of the flight cards furnished some information about effect of temperature and clouds. Some 84 cards contained 93 specific comments about the air temperature and the turbulence occurrence. Some reports were very explicit such as "temperature drop from $-45^{\circ}$ to $-55^{\circ} \mathrm{C}$. on first bump". Another stated "temperature $-46^{\circ} \mathrm{C}$. before turbulence

TABLE 8.-Effect of fight direction

\begin{tabular}{|c|c|c|c|c|c|}
\hline \multirow{2}{*}{ Flight direction } & \multirow{2}{*}{$\begin{array}{l}\text { Total } \\
\text { flights }\end{array}$} & \multicolumn{2}{|c|}{$\begin{array}{l}\text { Turbulence of } \\
\text { any intensity }\end{array}$} & \multicolumn{2}{|c|}{$\begin{array}{l}\text { Modetate or severe } \\
\text { turbulence }\end{array}$} \\
\hline & & Total & Percent & Total & Percent \\
\hline $\begin{array}{l}\text { East } \\
\text { West } \\
\text { North } \\
\text { South } \\
\text { Combined east-west } \\
\text { Combined north-south }\end{array}$ & $\begin{array}{l}437 \\
464 \\
152 \\
124 \\
901 \\
276\end{array}$ & $\begin{array}{r}316 \\
329 \\
103 \\
89 \\
645 \\
192\end{array}$ & $\begin{array}{l}72.3 \\
70.9 \\
67.8 \\
71.8 \\
71.6 \\
69.6\end{array}$ & $\begin{array}{r}93 \\
98 \\
26 \\
25 \\
191 \\
51\end{array}$ & $\begin{array}{l}21.3 \\
21.1 \\
17.1 \\
20.2 \\
21.2 \\
18.5\end{array}$ \\
\hline
\end{tabular}

$-41^{\circ} \mathrm{C}$. during turbulence, and $-46^{\circ} \mathrm{C}$. after turbulence." Others were quite vague including one remark "slight temperature rise." One pilot stated that he encountered no turbulence but noted an abrupt $12^{\circ} \mathrm{C}$. drop in an area in which turbulence had been forecast.

Of the 93 comments on temperature change, 37 (or 40 percent) reported a temperature rise, 49 (or 53 percent) reported a temperature fall, and 7 (or 7 percent) indicated no temperature change. The average temperature change was $4.4^{\circ} \mathrm{C}$. for light turbulence and $5.4^{\circ} \mathrm{C}$. for moderate or severe turbulence.

The fact that there were only 84 cards with comments on temperature does not mean that only 10 percent of the flights encountered a change in temperature. The changes were often quite sudden-one report mentioned a rise of $7^{\circ} \mathrm{C}$. in $2 \mathrm{~min}$., and in many cases the temperature returned to normal after the turbulence ceased. A pilot, not anticipating a temperature change, might well have failed to notice the change. It is possible that temperature changes such as these might prove to be sufficient to provide some warning of individual turbulence patches.

The pilots were not instructed specifically to note the cloud type other than to note whether they were in the vicinity of towering cumuli or thunderstorms when they encountered turbulence. However, there were a few cards with some remarks on clouds. Several reports mentioned stratiform clouds but these were at such a low level that it is doubtful whether they could be related to the turbulence. Two reports, one over the southern Rockies and one over the southern Appalachians, noted lenticular clouds, suggesting mountain wave activity. Cirriform clouds, generally at or near flight level, were mentioned a few times in connection with reported turbulence, but there were not enough reports to indicate any definite relationship. It may be possible that some cirrus clouds may provide a valuable visual warning of some turbulent patches.

However, it was possible to obtain some additional indications from the sky cover reported on the flight cards. The pilots were asked to indicate whether it was clear, scattered, broken, or overcast above, at, and below flight, level. There are no indications of the cloud type, but it. can probably be assumed that the clouds above and at, flight level were predominantly of the cirrus type. It was not possible to make much use of the cloud data below. flight level since these might be just below or at a great.

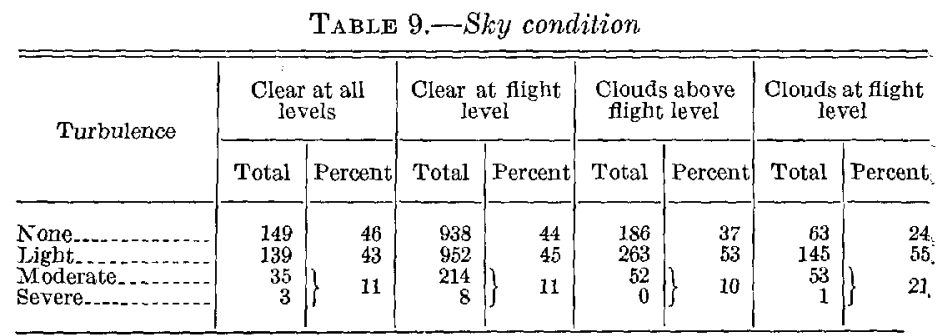


distance below in which case the clouds could be of middle or lower categories. Many cards could not be used since it could not be determined whether it was actually clear at all levels or the pilot did not fill out the cloud data. From the valid cards, an entry was made each time an occurrence or non-occurrence was made on the card. The results, which are summarized in table 9 , indicate that there is an increasing probability of turbulence when clouds were present above the flight level and an even greater chance with clouds present at flight level. This supports the view that high-level turbulence is associated with the presence of cirrus clouds. At the same time, these results indicate that turbulence was also present on a large number of occasions with no clouds present at flight level or even with no clouds at any level. The number is probably much greater than indicated since many of the discarded cards may well have actually had no clouds.

\section{SUMMARY}

This study points out the importance of the use of probability in the analysis and forecast of high-level turbulence. The results indicate that vertical wind shear is one of the most effective parameters. Other useful parameters include the presence of the jet stream, wind speed, and Richardson number. However, this study suggests that no one meteorological parameter will be sufficient in the understanding and forecasting of high-level turbulence over the entire country. It is felt that all parameters must be considered to more completely understand and forecast high-level turbulence.

Apparently more than one mechanism is effective in the production of the small-scale turbulent eddies in different meteorological or synoptic patterns. It appears that the turbulence associated with a strong jet stream circulation should be treated differently from that occurring over major mountain barriers and from those occurrences associated with major troughs. It may well be that the turbulence associated with cirrus cloud patterns should be considered separately. Separate forecast techniques and criteria may be necessary in the different patterns.

The results from this and other studies ([2], [5], [12], [13], [14], and [15]) suggest the following forecast guidelines:

1. Jet Stream. The addition of vertical wind shear and wind speed criteria should prove useful in eliminating some segments along the jet which do not show turbulence.

2. Mountain Wave Associated Turbulence. The occurrences associated with mountain wave situations usually result from a moderately strong flow normal to the ridge, very little change in wind direction with height, an increase in wind speed with height, and the presence of relatively stable layers. There does not appear to be the need for large horizontal or excessively large vertical wind shears. The Richardson numbers may be quite high in these stable layers.

3. Major Troughs. It appears that a combination of a large vector horizontal wind shear and a low Richardson number may be most useful. Vertical motion may prove to be an additional important parameter.

4. High Pressure Circulations. It appears that the turbulence occurrences in these circulations will be associated with low Richardson numbers caused by the proper combination of vertical wind shear and low stability in certain layers.

\section{REFERENCES}

1. L. H. Clem, "Clear Air Turbulence from 25,000 to 45,000 feet over United States," U.S. Air Weather Service, AWS TR $105-47,1954$.

2. D. Colson, "Analysis of Clear Air Turbulence During April 1960," Monthly Weather Review, vol. 89, No. 3, Mar. 1961, pp. 94-98.

3. J. J. George, A Method for the Prediction of Clear Air Turbulence, Eastern Air Lines, Atlanta, Ga., Aug. 1960.

4. H. T. Harrison, "The Use of Horizontal Wind Shear in Forecasting High Level Clear Air Turbulence," United Air Lines, Inc., Meteorology Circular No. 49, Denver, Colo., July 15, 1959.

5. D. Colson, "Meteorological Problems in Forecasting Mountain Waves," Bulletin of the American Meteorological Society, vol. 35, No. 8, Oct. 1954, pp. 363-371.

6. K. Brundige, "A Preliminary Study of Eleven Project Jet Stream Flights," Final Report, Contract AF19(604)-1565, Texas A and M College, 1958.

7. C. Mook, "A Meteorological Analysis of Reports of Turbulence Encountered by Aircraft in Clear Air," Aeronautical Enginoering Review, vol. 9, 1952, pp. 22-27.

8. H. Lake, "A Meteorological Analysis of Clear Air Turbulence," Geophysical Research Paper No. 47, U.S. Air Force Cambridge Research Center, 1956.

9. E. R. Reiter, "The Detailed Structure of the Wind Field near the Jet Stream," Journal of Meteorology, vol. 18, No. 1, Feb. 1961, pp. 9-30.

10. A. Anderson, "Free Air Turbulence," Journal of Meleorology, vol. 14, No. 6, Dec. 1957, pp. 477-494.

11. N. Pinus, "Atmosfernaâ turbulentnost', soizmerimaâ s razmerami samoletov [Atmospheric Turbulence of Dimensions Which Affect Aircraft]," Izvestiza, Akademira Nauk SSSR, Serin Geofizicheskañ, No. 3, 1957, pp. 395-400. (Translated by B. Cynk, English Language Edition, issued 1958.)

12. S. Kroll and J. D. Rustenbeck, "Clear Air Turbulence over Southeastern United. States, December 12-15, 1960," U.S. Weather Burean Manuscript, May 1961.

13. D. Colson and J. D. Rustenbeck, "Clear Air Turbulence over" Western United States, October 8-12, 1960," U.S. Weather Bureau Mannscript, June 1961: :

14. D. Colson, "Importance of Stability in Clear Air Turbulence Activity aver Western United States for December 4-10, 1960," U.S. Weather Bureau Manuscript, June 1961.

15. D. Hanson and others, "Procedures for Forecasting Clear Air. Turbulence," Office of Forecast Development, Technical Note No. 5, U.S. Weather Bureau, Jan. 1962. 